OPEN ACCESS

Edited by:

David Christopher Nieman Appalachian State University, United States

Reviewed by:

Gareth A. Wallis,

University of Birmingham, United Kingdom

*Correspondence:

Yannis Pitsiladis

y.pitsiladis@brighton.ac.uk

Specialty section:

This article was submitted to Sport and Exercise Nutrition,

a section of the journal

Frontiers in Sports and Active Living

Received: 10 January 2022

Accepted: 18 January 2022

Published: 17 February 2022

Citation:

Jonvik KL, King M, Rollo I, Stellingwerff $T$ and Pitsiladis $Y$ (2022) New Opportunities to Advance the

Field of Sports Nutrition.

Front. Sports Act. Living 4:852230. doi: 10.3389/fspor.2022.852230

\section{New Opportunities to Advance the Field of Sports Nutrition}

\author{
Kristin L. Jonvik ${ }^{1}$, Michelle King $^{2}$, lan Rollo ${ }^{3}$, Trent Stellingwerff ${ }^{4,5}$ and Yannis Pitsiladis ${ }^{6 *}$ \\ ${ }^{1}$ Department of Physical Performance, Norwegian School of Sport Sciences, Oslo, Norway, ${ }^{2}$ Gatorade Sports Science \\ Institute, PepsiCo Life Sciences, Barrington, IL, United States, ${ }^{3}$ Gatorade Sports Science Institute, PepsiCo Life Sciences, \\ Global R\&D, Leicestershire, United Kingdom, ${ }^{4}$ Canadian Sport Institute-Pacific, Victoria, BC, Canada, ${ }^{5}$ Exercise Science, \\ Physical and Health Education, University of Victoria, Victoria, BC, Canada, ${ }^{6}$ School of Sport and Health Sciences, University \\ of Brighton, Eastbourne, United Kingdom
}

Sports nutrition is a relatively new discipline; with $\sim 100$ published papers/year in the 1990s to $\sim 3,500+$ papers/year today. Historically, sports nutrition research was primarily initiated by university-based exercise physiologists who developed new methodologies that could be impacted by nutrition interventions (e.g., carbohydrate/fat oxidation by whole body calorimetry and muscle glycogen by muscle biopsies). Application of these methods in seminal studies helped develop current sports nutrition guidelines as compiled in several expert consensus statements. Despite this wealth of knowledge, a limitation of the current evidence is the lack of appropriate intervention studies (e.g., randomized controlled clinical trials) in elite athlete populations that are ecologically valid (e.g., in real-life training and competition settings). Over the last decade, there has been an explosion of sports science technologies, methodologies, and innovations. Some of these recent advances are field-based, thus, providing the opportunity to accelerate the application of ecologically valid personalized sports nutrition interventions. Conversely, the acceleration of novel technologies and commercial solutions, especially in the field of biotechnology and software/app development, has far outstripped the scientific communities' ability to validate the effectiveness and utility of the vast majority of these new commercial technologies. This mini-review will highlight historical and present innovations with particular focus on technological innovations in sports nutrition that are expected to advance the field into the future. Indeed, the development and sharing of more "big data," integrating field-based measurements, resulting in more ecologically valid evidence for efficacy and personalized prescriptions, are all future key opportunities to further advance the field of sports nutrition.

Keywords: innovation, wearables, technology, performance, health, diet, wellness, athletes

\section{INTRODUCTION}

Innovation has always been at the forefront of sport. Recent examples include drafting in cycling, clap skates in speed skating and more recently, carbon plate shoes in running. Sports nutrition is a relatively young discipline with $<100$ scientific papers published per year in the early 1990s, to about 3,500 per year today and a myriad of books (Figure 1). Much of this progress was brought about by exercise physiologists who developed new methods and technologies within their laboratories (e.g., treadmills and ergometers) at universities around the world to study trained 


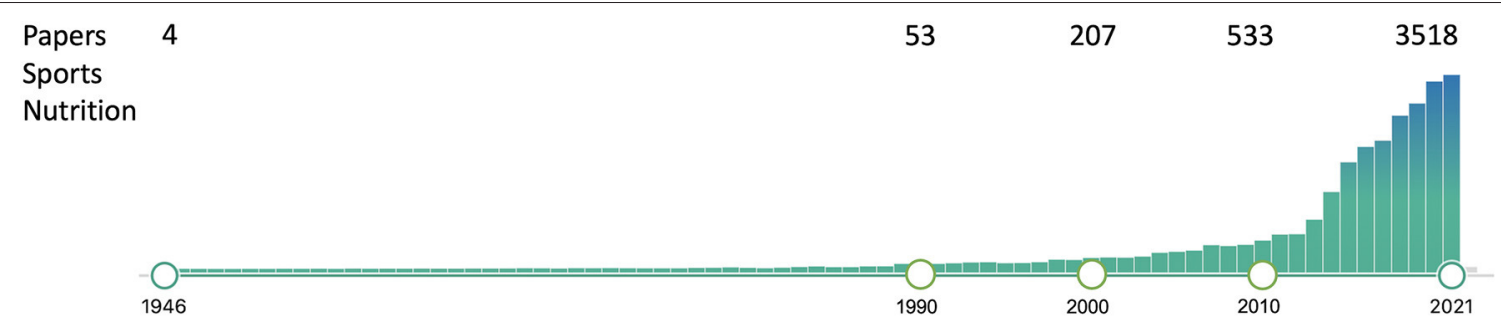

FIGURE 1 | Publications in Pubmed using the search term "Sports Nutrition" as of December, $2021^{1}$.

athletes (e.g., distance runners and cyclists) (Hawley et al., 2015). Next to sports science, these developments promoted the emergence of another new discipline, that of sports nutrition. Some of the major innovations and corresponding knowledge milestones for sports nutrition research, combined with sports science research, are summarized in Figure 2.

In 2003, the International Olympic Committee (IOC) working group on sports nutrition concluded "The amount, composition, and timing of food intake can profoundly affect sports performance. Good nutritional practice will help athletes train hard, recover quickly and adapt more effectively with less risk of illness and injury" (IOC Consensus Statement on Sports Nutrition, 2004). Nearing two decades later and these recommendations remain as pertinent. Despite all this progress, excitement and scientific endeavor, the ability to determine the impact of sports nutrition for different groups of athletes (e.g., different sports, ethnic groups, and sex) is still elusive. For example, there is substantial evidence for carbohydrate $(\mathrm{CHO})$ ingestion before, during and after exercise (Burke et al., 2011; Stellingwerff and Cox, 2014). However, it is difficult to separate the performance benefits of $\mathrm{CHO}$ ingestion per se vs. all other variables during competition (e.g., environment, competition, technology, equipment, and psychology).

Failure to establish the impact of any sports and exercise science intervention may result in a decline in recognition of the disciplines role in supporting the health and performance of athletes. This applies not only to the elite performers but also the young athlete, the exercising public, and the elderly. Therefore, this mini-review will focus on the opportunities to accelerate knowledge and practice of sports nutrition via the integration of technological innovations. We first highlight the present knowledge then propose ways of integrating technical advances and personalized prescription. Particular reference will be given to personalized prescriptions that are transforming and modernizing other life sciences.

\section{THE PRESENT}

Although, we primarily think of innovation in sports nutrition as directed at athlete performance outcomes, we also need to be innovative in our methods of synthesizing and dispersing

\footnotetext{
https://pubmed.ncbi.nlm.nih.gov/?term=sports+nutrition\&filter=years. 1946-
} 2021\&timeline $=$ expanded\&sort $=$ date\&sort_order=asc. research. The sports nutrition research data generated to date, have been compiled in several consensus documents on general sports (Thomas D. T. et al., 2016), team sports (Collins et al., 2021), and dietary supplements (Maughan et al., 2018). However, a limitation of the current evidence base informing all sport science and sports medicine consensus guidelines is the lack of appropriate intervention studies (e.g., randomized controlled clinical trials) in elite populations (McKay et al., 2022) that are ecologically valid (e.g., in real-life training and competition settings). Furthermore, often in practice, sports nutrition recommendations are retrospective fitted to sports in which the original research was not completed. For example much of the research to inform "stop-and-go" type sports has primarily been completed in soccer (Williams and Rollo, 2015). There is also a primary focus on male subjects in the sports nutrition literature in general; yet most guidelines are "assumed" to be ideal for females as well. Furthermore, in the last 5 years, the focus has shifted from original research to reviews in the area of sports nutrition. Of the published articles, between 17.6 and $20.2 \%$ have been reviews (512-570), of which 4.4-6.0 metaanalyses (128-223). Some of this focus on reviews of all types rather than original research is enforced due to restrictions imposed due to Covid-19. However, there is a continuing need for original research in order to advance the discipline.

Consensus meetings and subsequent statements are fundamental in the generation of expert driven guidelines. Over the past 5 years, consensus statements in Sports Nutrition ranged between 0.3 and $0.5 \%$ (Williams and Rollo, 2015; Jeukendrup, 2017; Pitsiladis et al., 2017; Sutehall et al., 2018; Burke et al., 2019; Stellingwerff et al., 2019; Baker et al., 2020; Muniz-Pardos et al., 2021) of the published articles. Historically, consensus statements, such as the International Olympic Committee (IOC) consensus on sports supplements (Maughan et al., 2018) are drafted following in-person meetings of leading medical and scientific content experts. However, it is appreciated that such meetings can be costly in terms of budget, time and the carbon footprint of travel. More recently, major consensus statements have implemented remote online approaches, including the entire 2019 World Athletics (formerly IAAF) Nutrition for Athletics Consensus Update (featuring over 40 authors across 17 papers, e.g., 12). A remote consensus approach provides the opportunity to involve a wider contribution on topic guidelines rather than fewer selected opinion leaders. Establishing online working communication platforms as well as documents may also allow consensus documents to be updated 


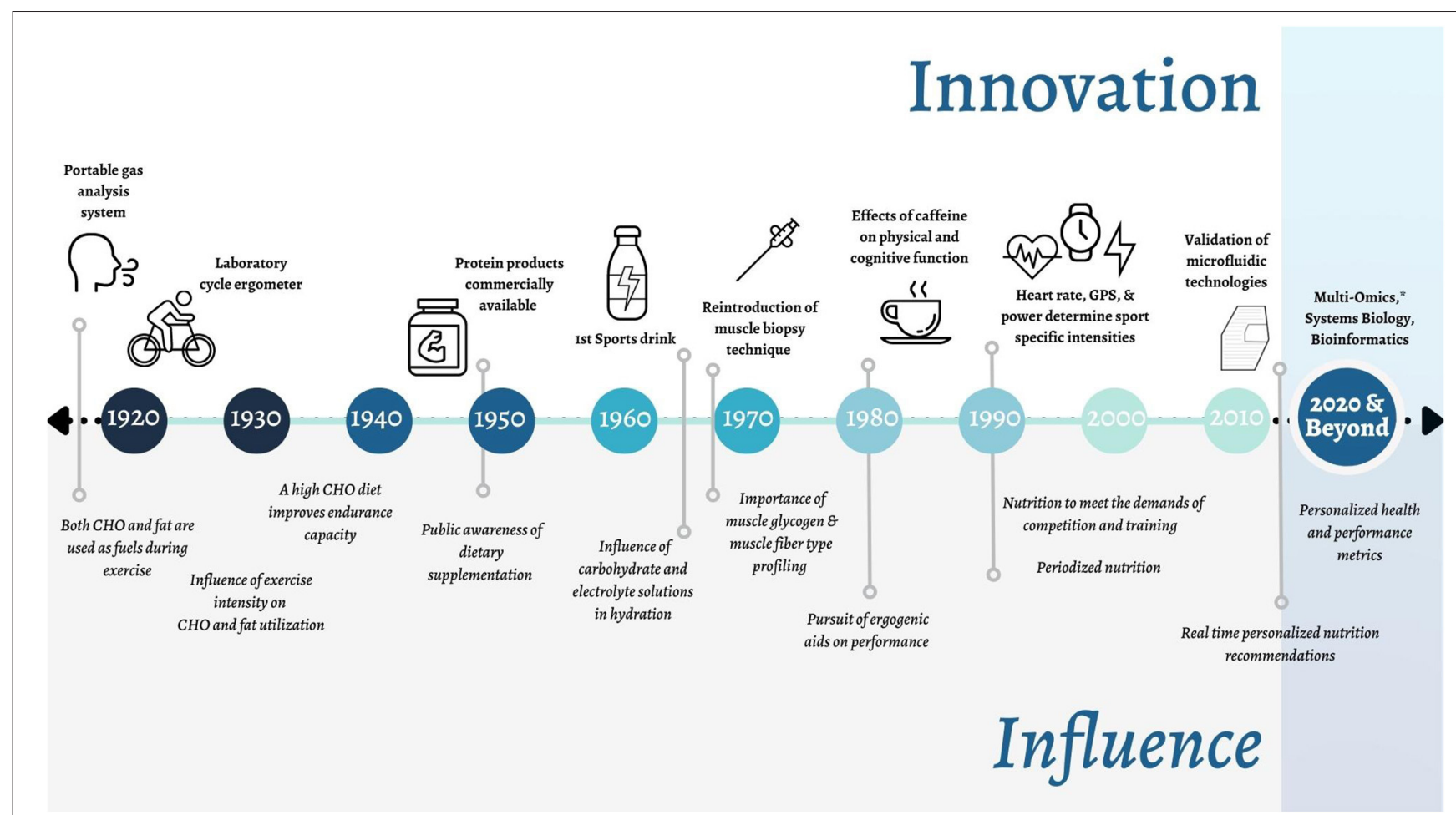

FIGURE 2 | Timeline of key innovations in Sports Nutrition and their respective influence on the field. *Including: genomics, transcriptomics, metabolomics, proteomics, phenomics, and other related omics (e.g., epigenomics).

with greater frequently or at pace with current literature. In summary, consensus statements informed by original research and meta-analyses, will require a greater reliance on new digital based approaches, while also respecting the need for in person meetings amongst experts.

\section{INTEGRATING TECHNICAL ADVANCES TO FIELD-BASED METRICS}

Most paradigms in sports nutrition have been established using laboratory experimentation, while neglecting evidence from in situ or field experimentation. This results in studies with limited ecological validity. In order to establish the efficacy of nutrition parameters for performance enhancement for all relevant populations, we need to better understand the competition demands of sport (Stellingwerff et al., 2019). Recent advances in wearable technologies and real-time monitoring have accelerated the shift in research from the laboratory to the field in order to enhance ecological validity. This trend poses a real opportunity for all sport science disciplines, including sports nutrition, to embrace these technological developments. One such recent example was the implementation of live performance feedback of athletes (during 10,000 m, marathon, and race-walk events) competing in the heat at Tokyo 2020 (Muniz-Pardos et al., 2021). Briefly, the aim of implementing this wireless technology during Tokyo Olympic Games was to help characterize the physiological and thermal strain experienced by athletes, as well as determine future management of athletes during a medical emergency as a result of a more timely and accurate diagnosis. The real-time monitoring comprised a smartwatch application, designed to collect, process and transmit a wide range of physiological, biomechanical, bioenergetics, and environmental data. This project was a success in terms of technological innovation but also general acceptance by athletes and sport's governing bodies. Such projects provide the opportunity for other new and valid sensors to assess performance- and healthrelated parameters particularly relevant to sports nutrition. One example is microfluidic technologies integrated into wearable patches to provide athletes instant feedback on sweat rate and sweat composition (Baker et al., 2020). Wider adoption of such technologies will create more symbiotic relationships between sport, health and technology by harnessing the unique demands of elite sport (e.g., the need for unobtrusive devices that provide real-time feedback).

Given their symbiotic relationship, the evolution of sports nutrition, and sports science requires more holistic approaches with input from all major disciplines (e.g., coaching science, environmental physiology, and sports biomechanics), stakeholders, sponsors, and interested industry (Pitsiladis et al., 2017). In recent years, physiology, nutrition, and technical advances have become increasingly integrated as part of new sport performance innovation strategies. A pertinent example is the Sub2 marathon project which was a novel proof-of-concept 
idea motivated by the need to focus on a holistic approach whilst promoting clean sport (i.e., high performance marathon running without doping) (Pitsiladis et al., 2017). This was the first dedicated international research initiative launched in 2014 made up of multidisciplinary scientists from academia, elite athletes and strategic industry partners across many sport science and medicine domains. An exciting Sub2 innovation with particular sports nutrition focus was the carbohydrate "hydrogel" development. This innovative concept in sports drinks was tested in elite athletes training in Ethiopia and Kenya. The novel aspect of the gel was that it allowed runners to ingest and tolerate $\mathrm{CHO}$ concentrations much higher than would normally be possible to ingest while running (e.g., 30\% CHO) (Sutehall et al., 2018). This was important because a common challenge for runners is to meet $\mathrm{CHO}$ ingestion guidelines without experiencing gastrointestinal complaints (Jeukendrup, 2017). This sports drink was subsequently trialed and tested in the field with positive response by elite runners during marathons and cyclists in the tour de France (Sutehall et al., 2020). One laboratory-based study has confirmed improved running performance, greater carbohydrate oxidation and lower GI symptoms following hydrogel ingestion compared with a standard $\mathrm{CHO}$ solution (Rowe et al., 2022). However, other laboratory-based studies have not reported any of these advantages following hydrogel ingestion compared to the ingestion of carbohydrate-electrolyte sport beverages (Baur et al., 2019; King et al., 2020; McCubbin et al., 2020). Nevertheless, it is a great example of sports nutrition innovation specific to the needs of the sport in the field. The hydrogel innovation was adopted by both the breaking ${ }^{2,3}$ and INEOS $159^{4}$ projects to break the 2 -h marathon barrier, a reflection of the perceived value of this putative innovation.

Combining emerging technologies are ideal to better our understanding of performance and to objectively test the impact of nutritional strategies in laboratory or real performance environments (Table 1). Such innovations will also allow other sports, beyond the mainly studied endurance sports cycling and running, to be evaluated in terms of sports nutrition impact. The utilization of these technologies, and co-ordinated research, may allow for the rapid generation of large data sets across many other types of sport that have yet to be included in sports nutrition research. As such, this approach will (i) speed our knowledge of sports that are difficult to study, (ii) gain data from regional populations under-represented in the literature, and (iii) inform the advice of how specific nutrition guidelines maybe transferred to the field. Accordingly, Table 1 highlights examples of existing and emerging technologies and methodologies that are "field-based" and relatively non-invasive that may continue to drive and refine sports nutrition research, interventions and recommendations.

The wearable/technological revolution promises in the near future to improve the ability to monitor a whole range of physiological parameters in the field. For example, apps, devices, and entire ecosystems are being developed and destined to

\footnotetext{
${ }^{2}$ www.runnersworld.com/uk/news/a29100149/breaking2.

${ }^{3}$ www.nike.com/gb/running/breaking2.

${ }^{4}$ www.ineos159challenge.com.
}

improve the quality of dietary intake methods and therefore the accurately of athletes' daily energy intake (EI) (Ferrara et al., 2019). These technological developments may enable the energy availability (EA) of individual athletes (i.e., calculated as EI-EEE/fat free mass) to be more accurately monitored. Correspondingly, a more comprehensively study of the athlete in situ would be possible. Thus, this approach represents an unprecedented opportunity to mitigate many unresolved issues in the field of sports nutrition such as relative energy deficiency in sport (RED-S) (Mountjoy et al., 2018). Importantly, the recent explosion of wearable technology/apps/devices with often unsubstantiated claims require quality assurance standards for wearable devices. Such concerns have prompted the International Federation of Sports Medicine (FIMS) to create a global standard for wearable devices in sport and fitness (Ash et al., 2020, 2021). Organizations involved in sports nutrition also have the opportunity to engage in quality assurance processes to safeguard the credibility of the innovations in sports nutrition.

\section{PERSONALIZED PRESCRIPTIONS}

There is no such thing as an "average" athlete. However, a key question is if there is an added value of personalized nutrition vs. general guidelines? Importantly, technology innovations will allow the individual response to a sports nutrition intervention to be determined. For instance, to find the individual recommendation of carbohydrate and fluid during exercise, we need knowledge about the energy demands of the sport, sweat losses, gastrointestinal limits, personal taste preferences and every element of the event. This needs to include research on different sport categories and target groups. This also presents the opportunity to follow athletes over a longer period of time, without associated human labor or time costs. For instance, to establish the extent to which an individual responds to different nutritional interventions, we need to conduct repeated testing in the same individual on several occasions. And the more complex the sport and its environment, the more test repetitions may be needed to establish the magnitude of impact of an intervention. It is also imperative that we determine athlete compliance with prescribed nutritional interventions. Such data will allow the evaluation of education and behavior change strategies, which may also provide opportunity for personalization.

The research on personalized sports nutrition will undoubtedly be the focus in the near future due to the technological advances in genomics technologies such as genetic sequencing. For instance, is has been suggested that the impact of DNA sequencing will become on a par with that of the microscope (Shendure et al., 2019). Sports nutrition and sports science are encouraged to use these powerful technologies and to keep up with rapid developments to increase the chances of finding the best solutions possible. Such technologies are routinely used in biomedical research and precision medicine applications, such as for cancer, stroke and Alzheimer's disease, thus, vital lessons can be learned and transferred to sports 
TABLE 1 | Examples of existing or potential "in field" non-invasive technologies or methodologies that may drive current or future nutrition studies, interventions, and/or recommendations.

\begin{tabular}{|c|c|c|c|}
\hline Theme & Innovation & Potential Nutrition Impact/Recommendations & References \\
\hline \multirow[t]{10}{*}{ Methodologies } & $\begin{array}{l}\text { Microfluidic technologies } \\
\text { integrated into wearable } \\
\text { patches }\end{array}$ & $\begin{array}{l}\text { Instant feedback on sweat rate and sweat composition } \\
\text { impaciting on hydration intake and fluid composition }\end{array}$ & Baker et al., 2020 \\
\hline & $\begin{array}{l}\text { Dual-energy X-ray } \\
\text { absorptiometry (DXA) }\end{array}$ & Reference standard to measure BMD & Nieves et al., 2010 \\
\hline & $\begin{array}{l}\text { Double labeled water (bolus } \\
\text { of } 2 \mathrm{H} 2180 \text { water, and } \\
\text { urinary collection) }\end{array}$ & $\begin{array}{l}\text { Gold standard methodology for measuring free-living total } \\
\text { daily energy expenditures, which can impact on projected } \\
\text { energetic nutrition requirements }\end{array}$ & $\begin{array}{l}\text { Speakman and Hambly, } \\
2016\end{array}$ \\
\hline & $\begin{array}{l}{[15 \mathrm{~N}] \text { glycine (bolus of tracer }} \\
\text { and urinary collection) }\end{array}$ & $\begin{array}{l}\text { Whole-body protein turnover (synthesis, breakdown, and net } \\
\text { protein balance) can be calculated by measurement of the } \\
\text { excretion rates of } 15 \mathrm{~N} \text { in urinary urea and ammonia }\end{array}$ & $\begin{array}{l}\text { Duggleby and Waterlow, } \\
2005\end{array}$ \\
\hline & Urinary ketone assessment & $\begin{array}{l}\text { Ability to better assess } \mathrm{CHO} \text { availability and/or ketogenic } \\
\text { adherence to adjust } \mathrm{CHO} \text { intake as required }\end{array}$ & Goffinet et al., 2017 \\
\hline & $\begin{array}{l}\text { Urinary specific gravity } \\
\text { assessment }\end{array}$ & It is an estimate of urine osmolality and hydration status & Surapongchai et al., 2021 \\
\hline & $\begin{array}{l}\text { Continuous glucose } \\
\text { monitoring assessment }\end{array}$ & Determine the dynamics of blood glucose concentration & Thomas F. et al., 2016 \\
\hline & Biomarkers & Tracking health, performance, and recovery in athletes & Lee et al., 2017 \\
\hline & Isotopic techniques & $\begin{array}{l}\text { The study of metabolic flux using stable isotope labeled } \\
\text { substrates }\end{array}$ & $\begin{array}{l}\text { Reisz and D'Alessandro, } \\
2017\end{array}$ \\
\hline & $\begin{array}{l}\text { DNA and RNA sequencing } \\
\text { of DNA and RNA }\end{array}$ & $\begin{array}{l}\text { The process of determining the nucleic acid sequence to } \\
\text { identify genes and gene expression (e.g., responders vs. } \\
\text { non-responders) }\end{array}$ & Shendure et al., 2019 \\
\hline \multirow[t]{3}{*}{ Food science } & $\begin{array}{l}\text { Glucose:Fructose sports } \\
\text { drink formulations }\end{array}$ & $\begin{array}{l}\text { Increase the amount of transportable and oxidizable } \mathrm{CHO} \text { to } \\
\text { increase endurance performance and decrease } \mathrm{Gl} \text { issues }\end{array}$ & Jeukendrup, 2010 \\
\hline & $\begin{array}{l}\mathrm{CHO} \text { hydrogel sports drink } \\
\text { formulations }\end{array}$ & $\begin{array}{l}\text { Increase the amount of gastric emptying resulting in } \\
\text { increased amount of transportable and oxidizable } \mathrm{CHO} \text { to } \\
\text { increase endurance performance and decrease } \mathrm{Gl} \text { issues }\end{array}$ & $\begin{array}{l}\text { Sutehall et al., 2018, 2020; } \\
\text { Rowe et al., } 2022\end{array}$ \\
\hline & $\begin{array}{l}\text { Slow-release beta-alanine } \\
\text { (containing cellulose type of } \\
\text { excipient) }\end{array}$ & $\begin{array}{l}\text { Decrease the amount of urinary losses of beta-alanine as well } \\
\text { as decrease the paraesthesia side-effects of beta-alanine as } \\
\text { a nutrition ergogenic aid }\end{array}$ & Décombaz et al., 2012 \\
\hline \multirow[t]{3}{*}{ Sport science/equipment integration } & Ergometer power meters & $\begin{array}{l}\text { Ability to more accurately estimate exercise energy } \\
\text { expenditure to better project energetic nutrition requirements }\end{array}$ & Haakonssen et al., 2013 \\
\hline & $\begin{array}{l}\text { Basic integrated activity } \\
\text { monitors (HR, GPS, and } \\
\text { accelerometry) }\end{array}$ & $\begin{array}{l}\text { Ability to more accurately estimate exercise energy } \\
\text { expenditure and exercise intensity to better project energetic } \\
\text { nutrition requirements }\end{array}$ & O’Driscoll et al., 2020 \\
\hline & $\begin{array}{l}\text { Advanced integrated activity } \\
\text { monitors (HR, GPS, } \\
\text { accelerometry, core, and } \\
\text { skin temperature) }\end{array}$ & $\begin{array}{l}\text { Ability to more accurately estimate in real-time exercise } \\
\text { energy expenditure, exercise intensity and core body } \\
\text { temperature to better project energetic nutrition, hydration } \\
\text { and cooling requirements coupled to pacing decisions }\end{array}$ & Muniz-Pardos et al., 2021 \\
\hline
\end{tabular}

Some identified technologies/methodologies continue to have construct validity challenges and require further research validation. $B M D$, bone mineral density; $\mathrm{CHO}$, carbohydrate; Gl, gastro-intestinal; GPS, global positioning system; HR, heart-rate.

nutrition. However, it is essential that these technological developments are not "oversold" and that their application in the field is founded on evidence-based research and not driven by commercial interests. At present, the use of genetic testing in both sports nutrition and sports science is at a very early stage. The consensus in the scientific literature being that genetic testing in sport science has very low clinical utility and should not be sold (Guasch-Ferré et al., 2018; Tanisawa et al., 2020). This is in contrast to the ever-increasing number of companies selling genetic testing, supported by unfounded claims (Webborn et al., 2015; Vlahovich et al., 2017; Tanisawa et al., 2020). The market value of genetic testing; USD 10.80
Billion in 2020, is forecast to reach USD 23.14 Billion by $2027^{5}$.

A more precision-based sports nutrition will also need to consider the other components of the "omics" cascade in addition to genomics (e.g., transcriptomics, metabolomics, proteomics, and single cell sequencing). Furthermore, such approaches may utilize powerful bioinformatics methods, such as machine learning and artificial intelligence to integrate the different layers of biological data required for understanding the functional consequences with the real time assessment of the "phenome"

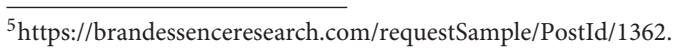


using $5 \mathrm{G}$ and 6G, sensors, devices and applications (Mancin et al., 2021). The identification of relevant non-invasive biomarkers are attractive to athletes and practitioners, due to the speed and increased frequency of collection vs. traditional blood draws or questionnaires. However, these technologies should be adopted in accordance with ethical principles and within national/international regulatory frameworks, which require further development.

\section{NEW APPROACHES TO FULFILL KNOWLEDGE GAPS}

Given recent technological breakthroughs, there are exciting opportunities for sports nutrition research to take gigantic leaps in the near future. Until now, most sports nutrition and sports physiology studies are performed in controlled laboratory environments and often study the effect of single nutrients. There is opportunity for sports nutrition research to embrace real world settings using real solutions and a more holistic approaches, such as performance benefits of whole foods, whole-body effects of low EA and "targeted nutritional periodization." One example is a study using tracer technologies to compare the effect of whole eggs vs. egg whites on post exercise muscle protein synthesis (van Vliet et al., 2017). New study designs should focus on real life settings that are strictly monitored with use of new technological advances, apps, and systems. As such, with a clear overview of nutritional demands of the sport and individual factors of impact, the extent of real-life effects of sports nutrition elements can be established.

Beyond the physiological impact of nutrients, there is also opportunity for sports nutrition research to study of cognitive and mental performance (Habay et al., 2021). This shift will require sports nutrition researchers and nutritionists to adopt and further develop technological methods to allow the psychobiological determinants of performance to better defined. New research paradigms and technologies could revolutionize sports nutrition research from small landmark studies of the 1960s with mainly the authors as subjects taking muscle biopsies on themselves (Bergström and Hultman, 1966), to the use of big data and collaboration between large groups of researchers. Examples of the latter are studies identifying genes implicated in hand grip strength involving over 195,000 subjects (Willems et al., 2017) or investigating the effects of age, body composition, and sex on total expenditure by the doubly labeled water method in 6,421 participants from 29 countries (Pontzer et al., 2021). The field of sports nutrition has the opportunity to adopt such collaborative practices combined with the application of the new and established technologies (see Table 1). It is reasonable to suggest that this approach will inevitably become the mainstay of personalized medicine, where treating the individual will be the norm rather than the average. If sports nutrition can embrace these challenges, it will thrive as an essential discipline and its relevance recognized in other fields (Oikawa et al., 2021).

\section{LIMITATIONS/PERSPECTIVES}

While innovations are necessary and appealing, there needs to be a considered approach to implementation. Soon almost any parameter will be able to be measured or inferred, yet the use of such data especially during live performances remains to be explored. There also seems to be a trend toward 24/7 observations (e.g., Apple watch, Oura ring, WHOOP, and Biostrap). Caution is encouraged when moving from too little or no assessment to over monitored and scheduled, as a result of too much feedback and reliance on devices. For instance, the athlete should be focussing on racing/competition, not on heart rate or temperature or non-validated feedback directly from a device. Tracking may also be potentially stressful (Andersen et al., 2020), albeit this remains to be determined in athlete populations. When evolving sports nutrition research with new technological advances, it is important to continuously question the application to practice as well as the reliability and reliance of devices.

The integration of new technologies in elite populations will also require closer collaborations between research and practitioners, and then directly to the athlete and coach (Bartlett and Drust, 2021). However, multidisciplinary sport science and medicine teams do not come without challenges and clear communication, roles and responsibilities are essential (Dijkstra et al., 2014) with the athlete and coach at the centre of accountability.

Finally, impactful implementation of these innovations and technological developments especially in elite athletic populations is going to require the continued and better integration of behavioral change psychology in sports nutrition. A recent systematic review highlighted some of the most effective behavioral strategies used in sports nutrition (Bentley et al., 2020).

\section{CONCLUSIONS}

Innovation is at the core of sports nutrition research and has pushed the field forward even before sports nutrition was recognized as a separate discipline. We are at a critical juncture in the evolution of this discipline primed to utilize new technologies to support the success of specific sports and individual athletes. Sharing data in new and more efficient ways, integrating field based physiological measures, and personalized prescriptions are key opportunities to advance sports nutrition. However, technological advances should not be used in haste and must first be evaluated to determine their functionality and value to the athletes health and performance. In summary, nutrition is but one of many complex and integrated sport performance determinants, and the impact of any new intervention should be assessed along a risk-reward continuum.

\section{AUTHOR CONTRIBUTIONS}

All authors listed have made a substantial, direct, and intellectual contribution to the work and approved it for publication. 


\section{REFERENCES}

Andersen, T. O., Langstrup, H., and Lomborg, S. (2020). Experiences with wearable activity data during self-care by chronic heart patients: qualitative study. J. Med. Internet Res. 22:e15873. doi: 10.2196/15873

Ash, G. I., Stults-Kolehmainen, M., Busa, M. A., Gaffey, A. E., Angeloudis, K., Muniz-Pardos, B., et al. (2021). Establishing a global standard for wearable devices in sport and exercise medicine: perspectives from academic and industry stakeholders. Sports Med. 51, 2237-2250. doi: 10.1007/s40279-021-01543-5

Ash, G. I., Stults-Kolehmainen, M., Busa, M. A., Gregory, R., Garber, C. E., Liu, J., et al. (2020). Establishing a global standard for wearable devices in sport and fitness: perspectives from the New England Chapter of the American College of Sports Medicine Members. Curr. Sports Med. Rep. 19, 45-49. doi: 10.1249/JSR.0000000000000680

Baker, L. B., Model, J. B., Barnes, K. A., Anderson, M. L., Lee, S. P., Lee, K. A., et al. (2020). Skin-interfaced microfluidic system with personalized sweating rate and sweat chloride analytics for sports science applications. Sci. Adv. 6, eabe3929. doi: 10.1126/sciadv.abe3929

Bartlett, J. D., and Drust, B. (2021). A framework for effective knowledge translation and performance delivery of Sport Scientists in professional sport. Eur. J. Sport Sci. 21, 1579-1587. doi: 10.1080/17461391.2020.1842511

Baur, D. A., Toney, H. R., Saunders, M. J., Baur, K. G., Luden, N. D., and Womack, C. J. (2019). Carbohydrate hydrogel beverage provides no additional cycling performance benefit versus carbohydrate alone. Eur. J. Appl. Physiol. 119, 2599-2608. doi: 10.1007/s00421-019-04240-4

Bentley, M. R. N., Mitchell, N., and Backhouse, S. H. (2020). Sports nutrition interventions: a systematic review of behavioural strategies used to promote dietary behaviour change in athletes. Appetite 150, 104645. doi: 10.1016/j.appet.2020.104645

Bergström, J., and Hultman, E. (1966). Muscle glycogen synthesis after exercise: an enhancing factor localized to the muscle cells in man. Nature 210, 309-310. doi: 10.1038/210309a0

Burke, L. M., Castell, L. M., Casa, D. J., Close, G. L., Costa, R. J. S., Desbrow, B., et al. (2019). International Association of Athletics Federations Consensus Statement 2019: nutrition for athletics. Int. J. Sport Nutr. Exerc. Metab. 29, 73-84. doi: 10.1123/ijsnem.2019-0065

Burke, L. M., Hawley, J. A., Wong, S. H. S., and Jeukendrup, A. E. (2011). Carbohydrates for training and competition. J. Sports Sci. 29(Suppl. 1), 17-S27. doi: 10.1080/02640414.2011.585473

Collins, J., Maughan, R. J., Gleeson, M., Bilsborough, J., Jeukendrup, A., Morton, J. P., et al. (2021). UEFA expert group statement on nutrition in elite football. Current evidence to inform practical recommendations and guide future research. Br. J. Sports Med. 55, 416. doi: 10.1136/bjsports-2019101961

Décombaz, J., Beaumont, M., Vuichoud, J., Bouisset, F., and Stellingwerff, T. (2012). Effect of slow-release $\beta$-alanine tablets on absorption kinetics and paresthesia. Amino Acids 43, 67-76. doi: 10.1007/s00726-011-1169-7

Dijkstra, H. P., Pollock, N., Chakraverty, R., and Alonso, J. M. (2014). Managing the health of the elite athlete: a new integrated performance health management and coaching model. Br. J. Sports Med. 48, 523-531. doi: 10.1136/bjsports-2013-093222

Duggleby, S. L., and Waterlow, J. C. (2005). The end-product method of measuring whole-body protein turnover: a review of published results and a comparison with those obtained by leucine infusion. Br. J. Nutr. 94, 141-153. doi: 10.1079/BJN20051460

Ferrara, G., Kim, J., Lin, S., Hua, J., and Seto, E. (2019). A focused review of smartphone diet-tracking apps: usability, functionality, coherence with behavior change theory, and comparative validity of nutrient intake and energy estimates. JMIR Mhealth Uhealth 7, e9232. doi: 10.2196/mhealth.9232

Goffinet, L., Barrea, T., Beauloye, V., and Lysy, P. A. (2017). Blood versus urine ketone monitoring in a pediatric cohort of patients with type 1 diabetes: a crossover study. Ther. Adv. Endocrinol. Metab. 8, 3-13. doi: $10.1177 / 2042018816681706$

Guasch-Ferré M., Dashti, H. S., and Merino, J. (2018). Nutritional genomics and direct-to-consumer genetic testing: an overview. Adv. Nutr. 9, 128-135. doi: 10.1093/advances/nmy001
Haakonssen, E. C., Martin, D. T., Burke, L. M., and Jenkins, D. G. (2013). Energy expenditure of constant- and variable-intensity cycling: power meter estimates. Med. Sci. Sports Exerc. 45, 1833-1840. doi: 10.1249/MSS.0b013e31828e18e6

Habay, J., Van Cutsem, J., Verschueren, J., De Bock, S., Proost, M., De Wachter, J., et al. (2021). Mental fatigue and sport-specific psychomotor performance: a systematic review. Sports Med. 51, 1527-1548. doi: 10.1007/s40279-021-01429-6

Hawley, J. A., Maughan, R. J., and Hargreaves, M. (2015). Exercise metabolism: historical perspective. Cell Metab. 22, 12-17. doi: 10.1016/j.cmet.2015.06.016

IOC Consensus Statement on Sports Nutrition (2004). Available online at: https://stillmed.olympic.org/Documents/Commissions_PDFfiles/ Medical_commission/IOC_CONSENSUS_STATEMENT_ON_SPORTS _ NUTRITION_2003.pdf (accessed December 14, 2021).

Jeukendrup, A. E. (2010). Carbohydrate and exercise performance: the role of multiple transportable carbohydrates. Curr. Opin. Clin. Nutr. Metab. Care 13, 452-457. doi: 10.1097/MCO.0b013e328339de9f

Jeukendrup, A. E. (2017). Training the gut for athletes. Sports Med. 47(Suppl. 1), 101-110. doi: 10.1007/s40279-017-0690-6

King, A. J., Rowe, J. T., and Burke, L. M. (2020). Carbohydrate hydrogel products do not improve performance or gastrointestinal distress during moderateintensity endurance exercise. Int. J. Sport Nutr. Exerc. Metab. 30, 305-314. doi: 10.1123/ijsnem.2020-0102

Lee, E. C., Fragala, M. S., Kavouras, S. A., Queen, R. M., Pryor, J. L., and Casa, D. J. (2017). Biomarkers in sports and exercise: tracking health, performance, and recovery in athletes. J. Strength Cond. Res. 31, 2920-2937. doi: $10.1519 /$ JSC. 0000000000002122

Mancin, L., Rollo, I., Mota, J. F., Piccini, F., Carletti, M., Susto, G. A., et al. (2021). Optimizing microbiota profiles for athletes. Exerc. Sport Sci. Rev. 49, 42-49. doi: 10.1249/JES.0000000000000236

Maughan, R. J., Burke, L. M., Dvorak, J., Larson-Meyer, D. E., Peeling, P., Phillips, S. M., et al. (2018). IOC consensus statement: dietary supplements and the high-performance athlete. Br. J. Sports Med. 52, 439-455. doi: 10.1136/bjsports-2018-099027

McCubbin, A. J., Zhu, A., Gaskell, S. K., and Costa, R. J. S. (2020). Hydrogel carbohydrate-electrolyte beverage does not improve glucose availability, substrate oxidation, gastrointestinal symptoms or exercise performance, compared with a concentration and nutrient-matched placebo. Int. J. Sport Nutr. Exerc. Metab. 30, 25. doi: 10.1123/ijsnem.2019-0090

McKay, A. K. A., Stellingwerff, T., Smith, E. S., Martin, D. T., Mujika, I., GooseyTolfrey, V. L., et al. (2022). Defining training and performance calibre: a participant classification framework. Int. J. Sports Physiol. Perform. 1-15. doi: 10.1123/ijspp.2021-0451

Mountjoy, M., Sundgot-Borgen, J. K., Burke, L. M., Ackerman, K. E., Blauwet, C., Constantini, N., et al. (2018). IOC consensus statement on relative energy deficiency in sport (RED-S): 2018 update. Br. J. Sports Med. 52, 687-697. doi: 10.1136/bjsports-2018-099193

Muniz-Pardos, B., Angeloudis, K., Guppy, F. M., Keramitsoglou, I., Sutehall, S., Bosch, A., et al. (2021). Wearable and telemedicine innovations for Olympic events and elite sport. J. Sports Med. Phys. Fitness 61, 1061-1072. doi: $10.23736 / \mathrm{S} 0022-4707.21 .12752-5$

Nieves, J. W., Melsop, K., Curtis, M., Kelsey, J. L., Bachrach, L. K., Greendale, G., et al. (2010). Nutritional factors that influence change in bone density and stress fracture risk among young female cross-country runners. $P M R$ 2, 740-750; quiz 794. doi: 10.1016/j.pmrj.2010.04.020

O’Driscoll, R., Turicchi, J., Beaulieu, K., Scott, S., Matu, J., Deighton, K., et al. (2020). How well do activity monitors estimate energy expenditure? A systematic review and meta-analysis of the validity of current technologies. $\mathrm{Br}$. J. Sports Med. 54, 332-340. doi: 10.1136/bjsports-2018-099643

Oikawa, S. Y., Brisbois, T. D., van Loon, L. J. C., and Rollo, I. (2021). Eat like an athlete: insights of sports nutrition science to support active aging in healthy older adults. Geroscience 43, 2485-2495. doi: 10.1007/s11357-021-00419-w

Pitsiladis, Y., Ferriani, I., Geistlinger, M., de Hon, O., Bosch, A., and Pigozzi, F. (2017). A holistic antidoping approach for a fairer future for sport. Curr. Sports Med. Rep. 16, 222-224. doi: 10.1249/JSR.0000000000000384

Pontzer, H., Yamada, Y., Sagayama, H., Ainslie, P. N., Andersen, L. F., Anderson, L. J., et al. (2021). Daily energy expenditure through the human life course. Science 373, 808-812. doi: 10.1126/science.abe5017 
Reisz, J. A., and D'Alessandro, A. (2017). Measurement of metabolic fluxes using stable isotope tracers in whole animals and human patients. Curr. Opin. Clin. Nutr. Metab. Care 20, 366-374. doi: 10.1097/MCO.0000000000000393

Rowe, J. T., King, R. F. G. J., King, A. J., Morrison, D. J., Preston, T., Wilson, O. J., et al. (2022). Glucose and fructose hydrogel enhances running performance, exogenous carbohydrate oxidation, and gastrointestinal tolerance. Med. Sci. Sports Exerc. 54, 129-140. doi: 10.1249/MSS.0000000000002764

Shendure, J., Balasubramanian, S., Church, G. M., Gilbert, W., Rogers, J., Schloss, J. A., et al. (2019). Publisher correction: DNA sequencing at 40: past, present and future. Nature 568:E11. doi: 10.1038/s41586-019-1120-8

Speakman, J. R., and Hambly, C. (2016). Using doubly-labelled water to measure free-living energy expenditure: some old things to remember and some new things to consider. Comp. Biochem. Physiol. A Mol. Integr. Physiol. 202, 3-9. doi: 10.1016/j.cbpa.2016.03.017

Stellingwerff, T., and Cox, G. R. (2014). Systematic review: carbohydrate supplementation on exercise performance or capacity of varying durations. Appl. Physiol. Nutr. Metab. 39, 998-1011. doi: 10.1139/apnm-2014-0027

Stellingwerff, T., Morton, J. P., and Burke, L. M. (2019). A framework for periodized nutrition for athletics. Int. J. Sport Nutr. Exerc. Metab. 29, 141-151. doi: 10.1123/ijsnem.2018-0305

Surapongchai, J., Saengsirisuwan, V., Rollo, I., Rendell, R. K., Nithitsuttibuta, K., Sainiyom, P., et al. (2021). Hydration status, fluid intake, sweat rate, and sweat sodium concentration in recreational tropical native runners. Nutrients 13:1374. doi: 10.3390/nu13041374

Sutehall, S., Galloway, S. D. R., Bosch, A., and Pitsiladis, Y. (2020). Addition of an alginate hydrogel to a carbohydrate beverage enhances gastric emptying. Med. Sci. Sports Exerc. 8, 1785-1792. doi: 10.1249/MSS.0000000000002301

Sutehall, S., Muniz-Pardos, B., Bosch, A., Di Gianfrancesco, A., and Pitsiladis, Y. (2018). Sports drinks on the edge of a new era. Curr. Sports Med. Rep. 17, 112-116. doi: 10.1249/JSR.0000000000000475

Tanisawa, K., Wang, G., Seto, J., Verdouka, I., Twycross-Lewis, R., Karanikolou, A., et al. (2020). Sport and exercise genomics: the FIMS 2019 consensus statement update. Br. J. Sports Med. 54, 969-975. doi: 10.1136/bjsports-2019-101532

Thomas, D. T., Erdman, K. A., and Burke, L. M. (2016). American College of Sports Medicine Joint Position Statement. Nutrition and athletic performance. Med. Sci. Sports Exerc. 48, 543-568. doi: 10.1249/MSS.0000000000000852

Thomas, F., Pretty, C. G., Desaive, T., and Chase, J. G. (2016). Blood glucose levels of subelite athletes during 6 days of free living. J. Diabetes Sci. Technol. 10, 1335-1343. doi: 10.1177/1932296816648344

van Vliet, S., Shy, E. L., Sawan, S. A., Beals, J. W., West, D. W., Skinner, S. K., et al. (2017). Consumption of whole eggs promotes greater stimulation of postexercise muscle protein synthesis than consumption of isonitrogenous amounts of egg whites in young men. Am. J. Clin. Nutr. 106, 1401-1412. doi: 10.3945/ajen.117.159855

Vlahovich, N., Hughes, D., Griffiths, L. R., Wang, G., Pitsiladis, Y. P., and Eynon, N. (2017). Genetic testing for exercise prescription and injury prevention: AIS-Athlome consortium joint statement. BMC Genomics 18(Suppl 8), 818. doi: 10.1186/s12864-017-4185-5

Webborn, N., Williams, A., McNamee, M., Bouchard, C., Pitsiladis, Y., Ahmetov, I., et al. (2015). Direct-to-consumer genetic testing for predicting sports performance and talent identification: Consensus statement. Br. J. Sports Med. 49, 1486-1491. doi: 10.1136/bjsports-2015-095343

Willems, S. M., Wright, D. J., Day, F. R., Trajanoska, K., Joshi, P. K., Morris, J. A., et al. (2017). Large-scale GWAS identifies multiple loci for hand grip strength providing biological insights into muscular fitness. Nat. Commun. 8, 16015. doi: $10.1038 /$ ncomms 16015

Williams, C., and Rollo, I. (2015). Carbohydrate nutrition and team sport performance. Sports Med. 45(Suppl 1), S13-S22. doi: $10.1007 /$ s40279-015-0399-3

Author Disclaimer: The views expressed in this article are those of the authors and do not necessarily reflect the position or policy of PepsiCo, Inc.

Conflict of Interest: IR and MK are employees of the Gatorade Sports Science Institute, a division of PepsiCo, Inc. KJ, TS, and YP, received speaking honoraria, for the GSSI ECSS 2021 pre-conference symposium which inspired this article. YP is the founding member of the Sub2 project (www.sub2hrs.com). The Sub2 project is affiliated to a non-trading company (Athlome Limited, UK) that is minor $(<1.1 \%)$ shareholder of Maurten AB, Gothenburg, Sweden.

Publisher's Note: All claims expressed in this article are solely those of the authors and do not necessarily represent those of their affiliated organizations, or those of the publisher, the editors and the reviewers. Any product that may be evaluated in this article, or claim that may be made by its manufacturer, is not guaranteed or endorsed by the publisher.

Copyright (c) 2022 Jonvik, King, Rollo, Stellingwerff and Pitsiladis. This is an openaccess article distributed under the terms of the Creative Commons Attribution License (CC BY). The use, distribution or reproduction in other forums is permitted, provided the original author(s) and the copyright owner(s) are credited and that the original publication in this journal is cited, in accordance with accepted academic practice. No use, distribution or reproduction is permitted which does not comply with these terms. 